\title{
A questão ambiental envolvendo os cemitérios no Brasil
}

\author{
The environmental issue involving cemeteries in Brazil \\ Pedro Daniel da Cunha Kemerich', Débora Cristina Bianchini², Julia Caroline Fank², \\ Willian Fernando de Borba ${ }^{3}$, Diego Polonia Weber ${ }^{4}$, Fernando Ernesto Ucker ${ }^{5}$

\footnotetext{
' Coordenador do Curso de Engenharia Ambiental da Universidade Federal de Santa Maria/CESNORS, Frederico Westphalen, Brasil. ${ }^{3}$ Técnico em Agropecuária, Aluno de Graduação do Curso de Engenharia Ambiental, Universidade Federal de Santa Maria, Santa Maria, Brasil.

${ }^{4}$ Pós-Graduação nível stricto sensu no Programa de Pós-Graduação em Engenharia de Processos na área de concentração, Universidade Federal de Santa Maria, Santa Maria, Brasil.
} \\ ${ }^{2}$ Acadêmicas do curso de Engenharia Ambiental e Sanitária, Universidade Federal de Santa Maria/CESNORS, Frederico Westphalen, Brasil. \\ ${ }^{5}$ Doutorando no curso de Agronomia, Universidade Federal de Goiás, Goiânia, Brasil.
}

\section{Resumo}

Sendo um tema recente e pouco debatido na sociedade atual, a questão ambiental envolvendo o sepultamento dos corpos humanos está sendo tema de muitas pesquisas que visam identificar fontes de contaminação causadas pelos mesmos. Este trabalho tem por objetivo abordar todas as temáticas que envolvem os cemitérios, muitas ainda desconhecidas pela população, mas de suma importância para a saúde pública. Sendo as necrópoles locais de sepultamento de cadáveres, existem riscos de contaminação do solo, do ar e dos recursos hídricos pelo necrochorume e os gases originados da putrefação, se o meio de sepultamento ou a área não forem adequados para tal finalidade. Somente a partir da homologação da Resolução CONANA Resolução 335/2003 essa questão começou a receber a atenção necessária. Há vários tipos de cemitérios, sendo os mais comuns os tradicionais, ou parques Jardins, onde o cadáver fica em contato direto com o solo, e os verticais, estes com melhor eficiência em termos ambientais e de saúde da população do entorno, sendo que a cultura dos povos é fator determinante para a escolha dos mesmos.

Palavras-chave: Cemitérios; Contaminação; CONAMA 335/2003

\begin{abstract}
The theme is a recent and little discussed in contemporary society, the environmental issue involving the burial of human bodies being the subject of many studies aimed at identifying sources of contamination caused by them. This work aims to address all issues involving cemeteries, still unknown to many people but of paramount importance for public health. Since the local necropolis burial of corpses, there are risks contamination of soil, air and water resources by necrochorume and putrefaction gases originated, if the means of burial or the area is not suitable for this purpose. Only after the approval of CONANA Resolution 335/2003 this issue began to receive the necessary attention. There are several types of cemeteries, and the most common traditional, parks or gardens where the body is in direct contact with the ground, vertical, those with better efficiency in terms of environment and health of the surrounding population, and the culture of the people determinant for the choice of the same factord.
\end{abstract}

Keywords: Cemeteries; Contamination; CONAMA 335/2003. 


\section{INTRODUÇÃO}

A prática de sepultar cadáveres é algo que acontece desde a Idade Média, a qual significa uma aproximação entre os cadáveres. Visto que era um período de inúmeras epidemias, muitos vitimados por doenças contagiosas eram enterrados em locais abertos e de maneira imprópria, o que acabou ocasionando a disseminação de agentes patogênicos. Por razões de saúde pública, foram implantados os cemitérios, sendo, então, proibido o sepultamento em locais impróprios, como terras de famílias ou igrejas.

A palavra cemitério, originária do grego Koumeterian e do latim Coemeteriun, significa dormitório, lugar onde se dorme, recinto onde se enterram ou se guardam os mortos e tem como sinônimos as palavras necrópole, carneiro, sepulcrário, campo-santo, cidade dos pés juntos e a última moradia (CAMPOS, 2007).

"Do ponto de vista científico, há um desconhecimento por parte da população sobre a influência ambiental que os cadáveres têm quando dispostos em um cemitério. Observando o cenário brasileiro, é alarmante a forma como as necrópoles vêm sendo gerenciadas. Em muito se pode assemelhar um cemitério com um aterro sanitário, visto que em ambos são enterrados materiais orgânicos e inorgânicos. Porém, há um agravante: a matéria orgânica enterrada no cemitério tem a possibilidade de carregar consigo bactérias e vírus que foram a causa da morte do indivíduo, podendo colocar em risco o meio ambiente e a saúde pública" (ANJOS, 2013).

Os cemitérios são fontes potenciais de contaminação ambiental, segundo KEMERICH et al. (2012a):

"Os cemitérios, como qualquer outra instalação que afete as condições naturais do solo e das águas subterrâneas, são classificados como atividade com risco de contaminação ambiental. A razão disso é que o solo em que estão instalados funciona como um filtro das impurezas depositadas sobre ele. O processo de decomposição de corpos libera diversos metais que formam o organismo humano, sem falar nos diferentes utensílios que acompanham o corpo e o caixão em que ele é sepultado. O principal contaminante na decomposi- ção dos corpos é um líquido conhecido como necrochorume, de aparência viscosa e coloração castanho-acinzentada, contendo aproximadamente $60 \%$ de água, $30 \%$ de sais minerais e $10 \%$ de substâncias orgânicas degradáveis."

Os problemas estruturais dos cemitérios podem ser considerados os principais agentes causadores da contaminação do solo e da água subterrânea com patógenos e metais pesados, em virtude de sua aplicação sem prévio estudo ambiental e da má conservação dos túmulos. Algumas soluções vêm sendo pensadas para acabar com esses problemas, como a construção de cemitérios horizontais, onde não há contato direto com o solo, evitado, assim, a contaminação.

O necrochorume gerado pela decomposição dos corpos humanos apresenta uma carga poluidora elevada e, em virtude do local onde se encontra, poderá atingir e contaminar o solo e os recursos hídricos superficiais e subterrâneos. O problema é agravado quando as necrópoles localizam-se em áreas de vulnerabilidade considerável e a população do entorno faz uso direto dos recursos hídricos sob a influência do mesmo, estando, assim, sujeita a doenças de veiculação hídrica (KEMERICH et al., 2012a).

Sendo assim, o presente estudo tem por objetivo elencar os principais impactos ambientais gerados pelos cemitérios, além de apresentar os tipos e as principais legislações vigentes que envolvem essa atividade.

\section{TIPOS DE CEMITÉRIOS}

Os cemitérios são monumentos, à memória daqueles que morreram, que os vivos fazem questão de perpetuar. Consequentemente, este tipo de construção adquiriu a condição de inviolabilidade no que tange à pesquisa científica nos seus diferentes aspectos. Entretanto, sociólogos, antropólogos, folcloristas e outros têm dado excelentes contribuições para um melhor conhecimento dos hábitos, costumes e práticas funerárias (MATOS, 2001).

No Brasil, quase sempre, a implantação dos mesmos tem sido feita em terrenos de baixo valor imobiliário ou com condições geológicas, hidrogeológicas e geotécnicas inadequadas. Este cenário poderá propiciar a ocorrência de impactos ambientais (alterações físicas, químicas e biológicas do meio onde está implantado o cemitério) e fenômenos conservadores, como a saponificação (PACHECO, 2006). 


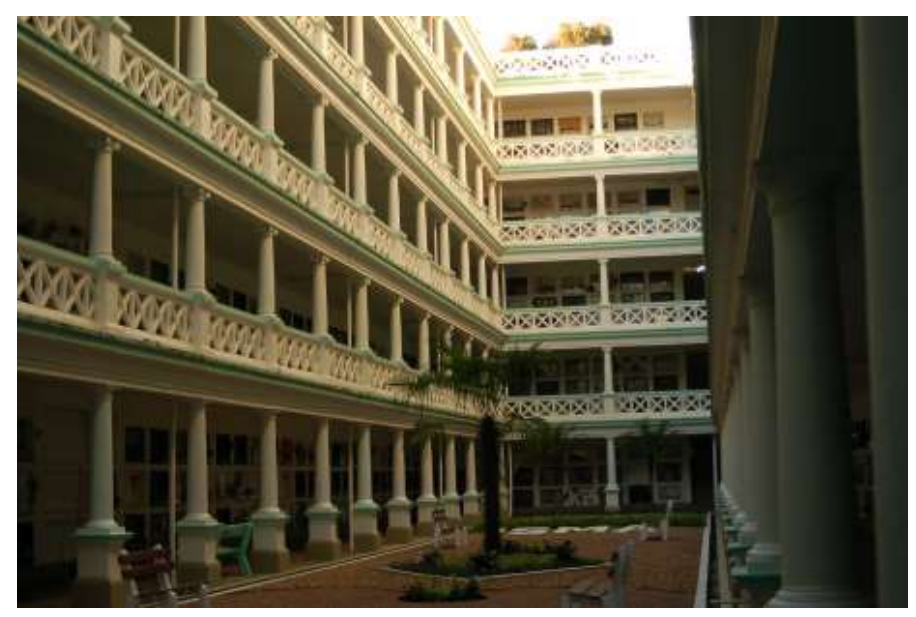

Figura 1. Cemitério vertical São Miguel e Almas em Porto Alegre - RS.

Fonte: http://interfacepinduca.files.wordpress.com/2013/06/dsc_1898.jpg

Entre os tipos de cemitérios existentes podemos citar os cemitérios verticais, os cemitérios tradicionais, crematórios e os campos ou jardins. Historicamente, havia a presença de tumbas, catatumbas e pirâmides, que não são mais usadas atualmente.

\section{I Cemitérios verticais}

Diante do demasiado crescimento urbano, surgiu a preocupação com os espaços cemiteriais, bem como a preocupação ambiental sobre o assunto. Pensando nisso, foram criados os cemitérios verticais, uma alternativa encontrada para solucionar o caso. Os cemitérios verticais são prédios de dois ou mais pavimentos que oferecem compartimentos, ou gavetas, para o sepultamento e que devem dispor de sistemas de inativação dos gases do necrochorume e de vedação, para que estes não cheguem às áreas comuns onde circulam os visitantes e funcionários do local.

O cemitério São Miguel e Almas (Figura 1) é um exemplo de cemitério vertical, criado no período das reformas higienístas, no Brasil:

Para os cemitérios verticais, a legislação atenta quanto à constituição dos lóculos: materiais que impeçam a passagem gasosa para os locais de circulação dos visitantes e trabalhadores; materiais com características construtivas que impeçam o vazamento do necrochorume; dispositivo que permita a troca gasosa proporcionando condições adequadas para a decomposição dos corpos; tratamento ambientalmente adequado dos efluentes gasosos (ANJOS, 2013).

Estas construções apresentam algumas vantagens, tais como: a utilização de menores áreas para sua construção, ausência de interfe- rência do necrochorume junto ao solo e às águas subterrâneas, baixa exigência quanto ao tipo de solo, facilidade de sepultamento, visitas em dias chuvosos, segurança, sepultamento no período noturno, entre outras (CAMPOS, 2007).

No quadro 1 podemos identificar os impactos ambientais do meio físico, biológico e sócio econômico na fase de operação de um cemitério vertical:

O maior cemitério vertical do mundo está na cidade de Santos. É a Memorial Necrópole Ecumênica, que foi criada em 1983 e possui mais de catorze mil lóculos, distribuídos em catorze andares (Figura 2):

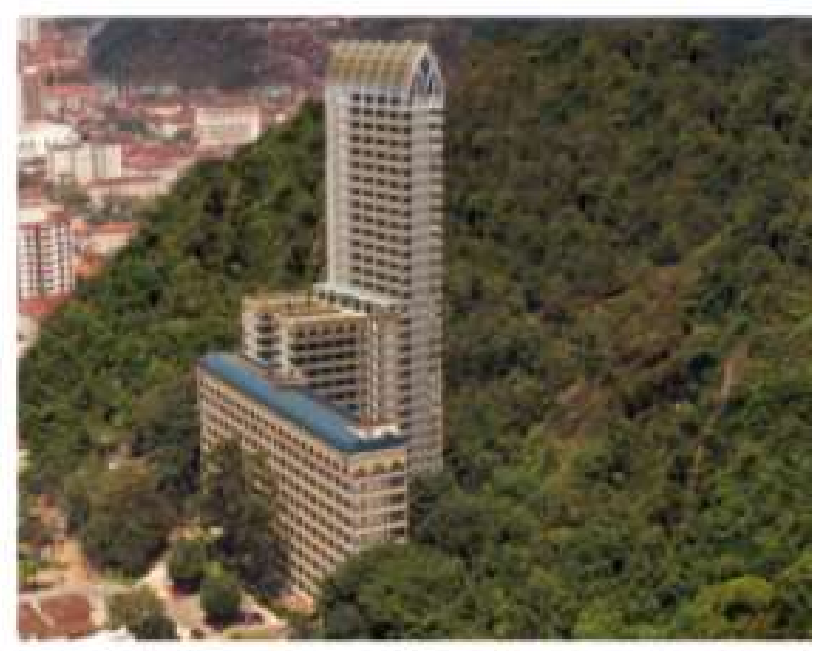

Figura 2. Memorial Necrópole Ecumênica de Santos, exemplo de cemitério vertical

Fonte: http://www2.uol.com.br/sciam/artigos/cemiterios_ como_fonte_de_contaminacao_ambiental.html 
Quadro 1. Impactos ambientais do meio físico, biológico e sócio econômico na fase de operação de um cemitério vertical.

\begin{tabular}{|c|c|c|}
\hline MEIO IMPACTADO & $\begin{array}{c}\text { IMPACTO } \\
\text { IDENTIFICADO }\end{array}$ & DESCRIÇÃO DO IMPACTO \\
\hline \multirow{5}{*}{ MEIO FÍSICO } & Impermeabilização & $\begin{array}{l}\text { A operação do cemitério vertical proporcionará a diminuição de áreas } \\
\text { permeáveis. Uma medida compensatória seria a implantação de projetos de } \\
\text { reaproveitamento de águas pluviais; }\end{array}$ \\
\hline & $\begin{array}{l}\text { Poluição por efluentes } \\
\text { liquidos }\end{array}$ & $\begin{array}{l}\text { Provenientes das áreas de apoio (sanitários e áreas administrativas). Deverão } \\
\text { ser destinadas à rede coletora de esgoto municipal e/ou fossa séptica com } \\
\text { filtro e sumidouro. }\end{array}$ \\
\hline & $\begin{array}{l}\text { Contaminação por } \\
\text { necrochorume }\end{array}$ & $\begin{array}{l}\text { Necrochorume é armazenado em bandeja de PVC ou fibra de vidro, é seco } \\
\text { por circulação do ar e polimerização; }\end{array}$ \\
\hline & $\begin{array}{l}\text { Poluição por residuos } \\
\text { sólidos }\end{array}$ & $\begin{array}{l}\text { Em periodos específicos, como finados, receberá grande fluxo de pessoas, } \\
\text { resultando em aumento na geração de resíduos sólidos. O empreendimento } \\
\text { deverá elaborar e seguir as diretrizes do Plano de Gerenciamento de Residuos } \\
\text { Sólidos (PGRS), conforme preconiza a legislação vigente. }\end{array}$ \\
\hline & $\begin{array}{l}\text { Alteração da qualidade } \\
\text { do ar }\end{array}$ & $\begin{array}{l}\text { As emissões atmosféricas serão provenientes da decomposição dos corpos. } \\
\text { Segundo Campos (2007), em cada sepultura (lóculo) deverá existir um tubo } \\
\text { de ventilação, interligando a um duto central para expelir os gases gerados na } \\
\text { decomposição. Estes gases deverão passar por um filtro de carvão ativado }\end{array}$ \\
\hline MEIO BIOLÓGICO & $\begin{array}{l}\text { Mudança de Paisagem } \\
\text { (ambiente) }\end{array}$ & $\begin{array}{l}\text { Uma medida compensatória para este impacto seria a implantação de } \\
\text { paisagismo local. Pode-se compor o cenário com árvores caducas e arbustos. } \\
\text { Recomenda-se o uso de Palmeira Imperial para o estacionamento e arbusto } \\
\text { floridos por trazer mais alegria ao local. }\end{array}$ \\
\hline \multirow{3}{*}{$\begin{array}{l}\text { MEIO SÓCIO } \\
\text { ECONÔMICO }\end{array}$} & $\begin{array}{l}\text { Alteração da taxa de } \\
\text { emprego }\end{array}$ & Na fase de operação ocorrerá geração de emprego. \\
\hline & $\begin{array}{l}\text { Aumento Fluxo de } \\
\text { veiculos }\end{array}$ & $\begin{array}{l}\text { Ocorrerá em dias especificos tais com: Finados; Cortejo funerário; Dia dos } \\
\text { Pais, Mães e das crianças. Para isso, o empreendimento deverá disponibilizar } \\
\text { vagas pela demanda por estacionamento; }\end{array}$ \\
\hline & $\begin{array}{l}\text { Alteração das atividades } \\
\text { comerciais e de serviços }\end{array}$ & $\begin{array}{l}\text { A operação do cemitério vertical proporcionará novas opções de } \\
\text { sepultamento, sendo considerado, portanto, como um impacto positivo para } \\
\text { a comunidade local. }\end{array}$ \\
\hline
\end{tabular}

Fonte: http://revista.ufrr.br/index.php/agroambiente/article/viewFile/894/1027

\subsection{Cemitérios tradicionais}

Segundo CAMPOS (2007), os cemitérios tradicionais são necrópoles compostas por alamedas pavimentadas, que contém túmulos semi-enterrados, mausoléus, capelas com altar, crucifixos e imagens, monumentos funerários revestidos de mármores e granitos, com pouca ou nenhuma arborização.

Esse tipo de sepultamento apresenta algumas desvantagens, tais como a possível contaminação das águas subterrâneas e superficiais, a ocupação de grandes áreas, devido à preocupação estética há um alto custo na sua construção e manutenção, interferência direta na estética urbana ou do local onde se encontra, e possível proliferação de insetos e animais que podem transmitir doenças, como mosquitos, escorpiões e baratas.

\subsection{Cemitério parque ou jardim}

Segundo a RESOLUÇÃO CONAMA $n^{\circ}$ 335 , de 3 de abril de 2003, alínea "b) cemitério parque ou jardim: é aquele predominantemente recoberto por jardins, isento de construções tumulares, e no qual as sepulturas são identificadas por uma lápide, ao nível do chão, e de pequenas dimensões".

Porém, esses tipos de necrópoles apresentam algumas desvantagens, como a falta de tratamento do necrochorume, uma vez que os corpos são enterrados sem que haja uma preocupação com a vedação para os líquidos e gases gerados, o que causa a contaminação do solo e das águas, bem como a possível proliferação de doenças.

\subsection{Crematórios}

O crematório destina-se à incineração de cadáveres. É composto por fornos com filtros para retenção de material particulado, que cremam corpos em compartimentos isolados. Cada corpo permanece durante uma hora no local e após esse período restam apenas cinzas, que são entregues aos familiares depois de sete dias, em uma urna apropriada (CAMPOS, 2007)

A instalação de crematórios apresenta como vantagens a não interferência do necrochorume nas águas subterrâneas, a destruição de microrganismos que poderiam interferir no ambiente e a ocupação de pequena área (CAMPOS, 2007). 
Existem algumas desvantagens, como a produção de resíduos originados da combustão dos corpos e, também, pela pouca aceitação, por questões religiosas, sociais e culturais da população.

A tendência é que aumente a procura por crematórios, visto que não há vagas nos cemitérios públicos e os particulares cobram altos preços, além do pagamento pela manutenção. Inclusive, não menos atenção merece a destinação dos restos mortais dos animais: aqueles que são abandonados são jogados no aterro comum, aqueles adotados, e tidos como membros da família que os adotou, são levados ao biotério de alguma faculdade, nas cidades que a possuem (WEBER, 2010).

\section{FORMAS DE CONTAMINAÇÃO}

\section{I Contaminação do solo}

Segundo a definição da EMBRAPA (2006), o solo é uma camada superficial constituída de partículas minerais e orgânicas, distribuídas em horizontes de profundidade variável, resultante da ação conjunta de agentes intempéricos sobre as rochas e a adaptação destas às condições de equilíbrio do meio em que se encontram expostas, geralmente diferentes daquele que condicionou sua gênese, apresentando variabilidade espacial.

A falta de medidas de proteção ambiental no sepultamento de corpos humanos em covas abertas no solo, ao longo dos últimos séculos, fez com que a área de muitos cemitérios fosse contaminada por diversas substâncias, orgânicas e inorgânicas, e por microrganismos patogênicos. Essa contaminação ocorre quando os cemitérios são implantados em locais que apresentam condições ambientais desfavoráveis (SILVA \& MALAGUTTI, 2010).

A contaminação do solo por meio do necrochorume atinge a zona não saturada, mas depende da estrutura hidrogeológica do local (ALCÂNTARA, 2010).

Em solos com alta umidade, há um processo conhecido como saponificação, pelo qual ocorre a quebra das gorduras corporais e a liberação de ácidos graxos. Esse composto liberado exibe alta acidez, o que inibe a ação de bactérias putrefativas, retardando, assim, o mecanismo de decomposição do cadáver e tornando o mecanismo tanto mais duradouro quanto mais contaminante. (KEMERICH et al., 2012b)

"Nos solos arenosos, os teores de areia superiores a $70 \%$ e o de argila inferior a $15 \%$. São solos que possuem boa aeração, permeáveis de baixa capacidade de retenção de água e baixos teores de matéria orgânica, dificultando o desenvolvimento de plantas e microrganismos. A reduzida capacidade de retenção de água nesses solos permite $\mathrm{o}$ arejamento das sepulturas (prolongando o processo de putrefação) e em períodos chuvosos ocorre a saturação dos solos o que propicia a saponificação dos corpos" (ALCÂNTARA, 2010).

\subsection{Contaminação das águas subterrâneas}

A degradação de corpos d'água é hoje um dos temas mais estudados pelas instituições públicas e federais, tendo como causa maior o crescimento desenfreado da população mundial, bem como o uso indevido da água. O intenso uso e exploração dos recursos hídricos, já limitados, nas atividades de produção e consumo estão degradando-os (KEMERICH et al. 2010)

As águas subterrâneas são aquelas que se encontram sob a superfície da Terra, preenchendo os espaços vazios existentes entre os grãos do solo, rochas e fissuras (rachaduras, quebras, descontinuidades e espaços vazios) (MINISTÉRIO DO MEIO AMBIENTE, 2007).

A infiltração das águas da chuva nos túmulos promove o transporte de muitos compostos químicos (orgânicos e inorgânicos) para o solo, que, dependendo das características geológicas do terreno, podem alcançar o aquífero, contaminando-o. Para a minimização desse risco é indispensável o monitoramento da qualidade da água nessas áreas (KEMERICH \& BORBA, 2013).

Os locais de operação impróprios para cemitérios urbanos podem provocar a contaminação de mananciais hídricos por microrganismos que se proliferam durante o processo de decomposição dos corpos. Caso ocorra a contaminação do aquífero freático na área interna do cemitério, não somente esta área estará potencialmente poluída, mas, sim, áreas arredores, aumentando, assim, o risco de ocorrências de doenças de veiculação hídrica nas pessoas que venham a utilizar desta água através de poços rasos.

$\mathrm{Na}$ Figura 3, podemos observar um esquema da contaminação de corpos d'água pelo nechochorume:

A transformação do corpo humano e a sua decomposição, ocorridas em lugares onde não há estudos hidrogeológicos e infraestrutura adequada, podem vir a causar significativos impactos físicos sobre o ambiente, sobretudo a contaminação das águas superficiais e subterrâneas por microorganismos que se proliferam ao se decomporem os 


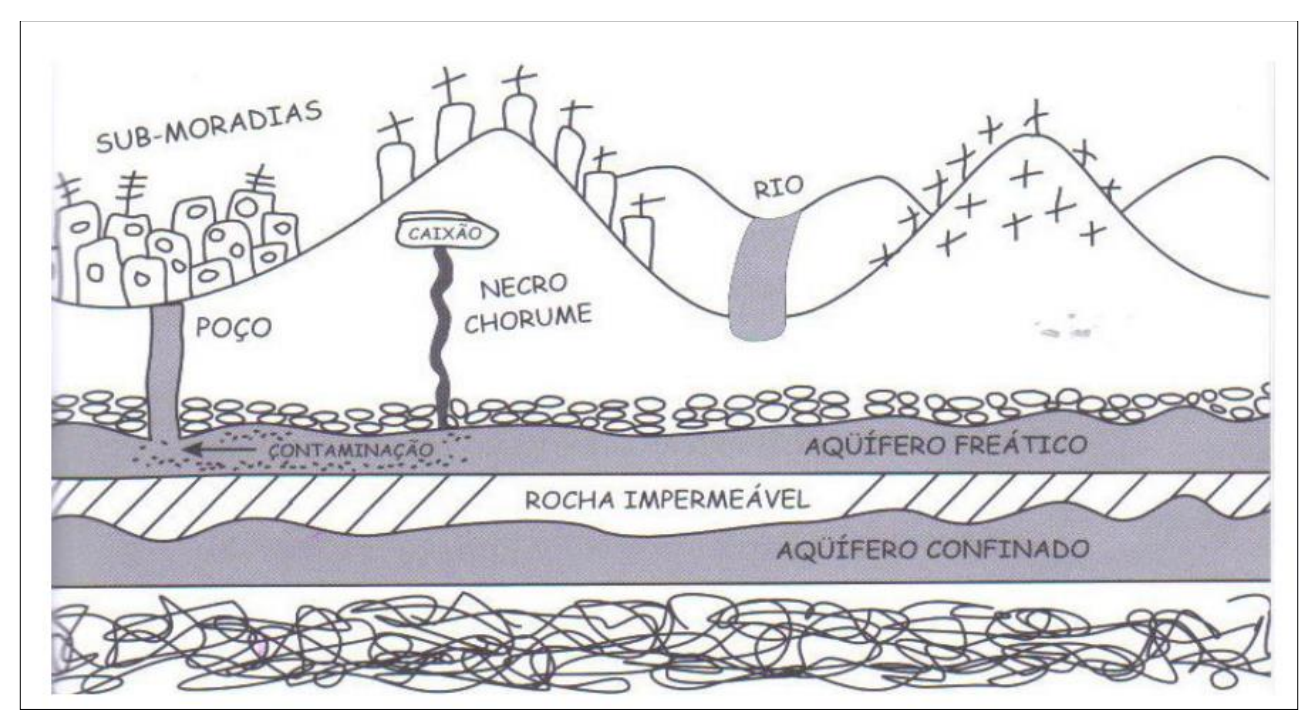

Figura 3. Esquema de contaminação do aquífero freático pelo necrochorume

Fonte: ANDRADE (2007)

corpos (BACIGALUPO, 2012).

"O necrochorume, produzido no processo de decomposição orgânica, por exemplo, é liberado de forma constante por cadáveres em decomposição e apresenta um grau variado de patogenicidade. Grande parte dos organismos patogênicos não tolera a presença de oxigênio disponível na zona insaturada do solo e acaba eliminada. Mas a uma maior profundidade, nos aqüíferos por exemplo, a escassez de oxigênio permite abundante desenvolvimento de microrganismos. No caso de a captação de água para consumo humano ou animal ser feita a partir de poços com pequena profundidade, pessoas e animais que se servirem dela estão sob risco de doenças provocadas pela presença desses organismos" (KEMERICH et al., 2012b).

A disposição dos corpos humanos, de forma inadequada, pode gerar problemas de poluição no aquífero subterrâneo, bem como no solo. Devido à ação das águas superficiais e das chuvas infiltradas nas sepulturas, ou pelo contato dos corpos com as águas subterrâneas, o necrochorume pode entrar em contato e contaminar estas águas (NEIRA et al., 2008).

O sepultamento de cadáveres gera fontes de poluição para o meio físico e, por isso, deve ser considerado como atividade causadora de impacto ambiental. No entanto, apesar da existência de alguns relatos em Berlim (Alemanha) e Paris (França), na década de 1970, apontando o posicionamento dos cemitérios em relação a fontes de água, como lençóis freáticos e nascentes, como uma das causas de epidemias de febre tifoide, esses locais nunca foram incluídos entre as fontes tradicionais de contaminação ambiental (SILVA \& MALAGUTTI, 2010)

A falta de medidas de proteção ambiental no sepultamento de corpos humanos, em pesquisas sobre esse tema, é recente. Em 1995, o hidrogeólogo Boyd Dent, da Universidade Tecnológica de Sidney (Austrália), constatou, em estudo no cemitério da cidade australiana de Botany, aumento da condutividade elétrica e da concentração de sais minerais em águas subterrâneas próximas de sepultamentos recentes (SILVA \& MALAGUTTI, 2010)

Outra ameaça produzida por cemitérios é a ineficiente gestão de resíduos, como as vestimentas que envolvem os corpos, incluindo restos de caixões. Esses resíduos, geralmente, são depositados nas proximidades das áreas de sepultamento e, em contato com a água da chuva, podem fazer com que diversas substâncias indesejáveis se infiltrem no solo e, também, atinjam as fontes hídricas (KEMERICH et al., 2012b).

\subsection{Contaminação do ar}

Os gases liberados pela decomposição do corpo, em alguns casos, também são tóxicos, por exemplo: H2S - Gás Sulfídrico - é extremamente tóxico e inflamável, causa danos à saúde, sendo até fatal. CH4 - Metano - a reação do metano é a combustão. NH3 - Amônia - tóxico e dissolve facilmente em água. CO2 - Dióxido de carbono - 
gás inodoro, incolor, sufocante. H2 - Hidrogênio - incolor, inodoro, sem sabor e não tóxico.

Além desses elementos característicos, outros gases são emitidos, como os óxidos metálicos (titânio, cromo, cádmio, chumbo, ferro, manganês, mercúrio e níquel entre outros), lixiviados dos adereços das urnas mortuárias, incluindo formaldeído e metanol utilizados na prática do embalsamento (KEMERICH et al., 2012b)

A poluição do ar implicará um grande aumento de casos de doenças respiratórias (como asma), de irritação dos olhos e de doenças cardiovasculares proeminentes da eliminação desses gases para atmosfera (SILVA, 1999).

Com isto, é aconselhável que o solo acima do caixão não seja compactado no reaterro para que haja maior aeração do corpo. Por outro lado, a aeração libera gases tóxicos e extremamente mal cheirosos para a atmosfera (CARNEIRO, 2009)

A cremação não libera fumaça em seu processo. De modo geral, o procedimento ocorre a temperaturas de $900{ }^{\circ} \mathrm{C}$, com duração de duas horas e captura de gases liberados pela queima. Dessa forma, a cremação é a solução póstuma de menor impacto ambiental, pois não gera resíduos convencionais com potencial de contaminar o ambiente, tanto no solo quanto na atmosfera. (KEMERICH et al., 2012b)

Em vista desses problemas causados ao ar atmosférico, alguns cemitérios possuem sistemas de captação dos gases gerados durante a decomposição, denominado de Processo de Decomposição Assistido por Calor e Pressão Negativa, é uma alternativa inovadora em não liberar o necrochorume, pois é imediatamente vaporizado, transformando-se em gases que são tratados no Inativador de Gases, que libera na atmosfera gases considerados respiráveis, sem praticamente qualquer dano a natureza, aprovado pela CETESB e CONAMA.

\section{LEGISLAÇÕES VIGENTES}

Na esfera federal, até o ano de 2003, não havia legislação específica ou norma técnica regulamentando a implantação e a operação de cemitérios em termos ambientais e sanitários (WEBER, 2010).

O Conselho Nacional de Meio Ambiente (CONAMA) promulgou a Resolução n ${ }^{\circ} 335$, que dispõem sobre o licenciamento ambiental de cemitérios. Esta lei foi reformulada em 28 de março de 2006, com a Resolução do CONAMA n 368. Porém, pode-se perceber que existem falhas nestas leis (FOFONKA \& KUNT, 2006).
Os cemitérios instalados antes da vigência da Resolução $\mathrm{n}^{\circ} 335$ devem se adaptar às suas regras, sendo que os órgãos estaduais e municipais de meio ambiente deverão estabelecer, até dezembro do corrente ano, os critérios para a adequação, conforme menciona o artigo 11, cuja redação foi dada pela Resolução CONAMA n ${ }^{\circ}$ 402, de 17 de novembro de 2008 (WEBER, 2010).

O subsolo da área pretendida para o cemitério deverá ser constituído por materiais com coeficientes de permeabilidade entre 10 -5 e 10 -7 $\mathrm{cm} / \mathrm{s}$, na faixa compreendida entre o fundo das sepulturas e o nível do lençol freático, medido no fim da estação das cheias. Para permeabilidades maiores, é necessário que o nível inferior dos jazigos esteja dez metros acima do nível do lençol freático (BRASIL, 2003. Art. 5, Paragrafo $1^{\circ}$, inciso III).

O perímetro e o interior do cemitério deverão ser providos de um sistema de drenagem adequado e eficiente, destinado a captar, encaminhar e dispor, de maneira segura, o escoamento das águas pluviais e evitar erosões, alagamentos e movimentos de terra (BRASIL, 2003. Resolução 335. Art.5, Parágrafo $1^{\circ}$, inciso II).

A Resolução proíbe a instalação de cemitérios em Áreas de Preservação Permanente ou em outras áreas que exijam desmatamento de Mata Atlântica primária ou secundária, em estágio médio ou avançado de regeneração, em terrenos predominantemente cáusticos, que apresentam cavernas, sumidouros ou rios subterrâneos, em áreas de manancial para abastecimento humano, bem como naquelas que tenham seu uso restrito pela legislação vigente, ressalvadas as exceções legais previstas (WEBER, 2010).

Nos cemitérios construídos mais recentemente, o risco de contaminação é bem menor. Desde 2003, a legislação estipula, entre outros itens, que não podem ocupar áreas de preservação ambiental, nem terrenos sob os quais o lençol freático passa a menos de $5 \mathrm{~m}$ de profundidade, além de dispor sobre normas para construção dos jazigos a fim de evitar a infiltração do necrochorume no solo (CHRISTANTE, 2011).

Para amenizar os impactos causados pelos cemitérios, as normas condicionam este tipo de empreendimento à realização do EIA/RIMA. Para que este relatório seja fornecido, é feito o estudo prévio de viabilidade, identificando as condições do local, tipo de solo, localização e profundidade do lençol freático. Além disso, a obra deve ser feita verificando outros fatores de importância que o terreno em questão necessite, para a implantação de um cemitério (WEBER, 2010). 


\section{CONCLUSÕES}

Com base na releitura feita nos tópicos acima, conclui-se que os cemitérios constituem potencial fonte de contaminação ambiental para o meio ambiente e para a saúde das pessoas. Seus problemas podem ser de veiculação atmosférica, hídrica, visual ou no solo em que estão instalados, problemas que são desconhecidos pela maioria da população.

A prática de enterrar os mortos em necrópoles tradicionais é a mais utilizada, visto sua demanda socioeconômica e costumes religiosos, porém, é o principal contaminante dos solos em unidades cemiteriais. Uma das principais alternativas são os cemitérios verticais, em que é possível realizar o tratamento dos gases gerados da putrefação, evitando, assim, a contaminação atmosférica.

A contaminação das águas subterrâneas é um dos principais agentes proliferadores de doenças, pois pode atingir grandes áreas, dependendo da extensão do lençol freático e de sua profundidade, em que pessoas podem utilizar destas águas para consumo próprio através de poços, sem que tenhase um prévio tratamento da qualidade da mesma.

As legislações vigentes sobre o assunto estão, aos poucos, tornando-se conhecidas e sendo cumpridas pelos municípios. Nelas é possível visualizar os padrões referentes à instalação correta de sepulcrários. Cumpridas as normas estabelecidas, o nível de contaminação pode ser reduzido ou evitado, melhorando, assim, a qualidade de vida das pessoas, as condições do meio ambiente e a paisagem urbana, visto que, geralmente, os cemitérios estão instalados nas cidades.

\section{REFERÊNCIAS}

ALCÂNTARA, L. A.; SANTOS, S. A. dos; KEMERICH, P. D. da C.; SILVA, R. F. da; Contaminação de recursos naturais por necrópoles. Revista Disciplinarium Scientia, Vol.11, p.17-28, 2010.

ANJOS, R. M. dos. Cemitérios: uma ameaça à saúde humana? CREA - SC. Out. 2013 Disponível em:http://www.crea-sc.org.br/portal/index.php?$\mathrm{cmd}=$ artigosdetalhe $\& \mathrm{id}=2635 \# . \mathrm{U} 2 \mathrm{KuDW}$ pdUpo Acessado em: 13 de Maio de 2014.

BACIGALUPO, R. Cémitérios: fontes potenciais de impactos ambientais. Revista História, Natureza e Espaço, Vol 1, p. 1-8, 2012.

BRASIL. Conselho Nacional de Meio Ambiente
- CONAMA. Resolução nº 335 de 2003. Brasília: CONAMA, 2003.

SILVA, R. W. da C.; MALAGUTTI FILHO, W. Cemitérios: fontes potenciais de contaminação Revista Ciência Hoje, Vol. 244, p. 24-29, 2009.

CAMPOS, A. P. S. Avaliação do potencial de poluição no solo e nas águas subterrâneas decorrente da atividade cemiterial. 2007. 141f. Dissertação (Mestrado em Saúde Pública) - Universidade de São Paulo, Faculdade de Saúde Pública, São Paulo, 2007.

CARNEIRO, V. S. Impactos causados por necrochorume de cemitérios: Meio ambiente e saúde pública. Disponível em: http://aguassubterraneas.abas.org/ asubterraneas/article/view/21956/14325 Acessado em: 13 de Maio de 2014.

CHRISTANTE, L. Poluição após a morte. Disponível em: http://www.unesp.br/aci_ses/revista_unespciencia/acervo/25/quem-diria Acessado em: 13 de Maio de 2014.

FOFONKA, L.; KUNT, P. da C. Cemitérios: potenciais fontes geradoras de impactos ambientais. Disponível em: http://www.revistaea.org/artigo. php?idartigo $=976 \&$ class $=02$ Acessado em: 13 de Maio de 2014.

KEMERICH, P. D. C.; BORBA, W. F.; SILVA, R. F.; BARROS, G.; GERHARDT, A. E.; FLORES, C. E. B. Valores anômalos de metais pesados em solo de cemitério. Revista Ambi-Agua, Taubaté, Vol.7, p. 140-156, 2012. b.

KEMERICH, P.D.C.; UCKER, F. E.; BORBA, W. F. Cemitérios Como Fonte de Contaminação Ambiental. Revista Scientific American Brasil, Vol.1, p. 78-81, 2012. a.

KEMERICH, P.D.C.; DESCOVI FILHO, L.L.V.; UCKER, F. E.; FOLETTO, C. V. Influência dos cemitérios na contaminação da água subterrânea em Santa Maria - RS. Revista Águas Subterrâneas (São Paulo), v. 24, p. 129-141, 2010.

KEMERICH, P.D.C.; BORBA, W. F. Cemitérios e os problemas ambientais: a dura realidade brasileira. Revista Conselho em Revista - CREA RS, v. 10, p. 36-37, 2013.

MATOS, B.A. Avaliação da Ocorrência e do Transporte de Microrganismos no Aqǘfero Freático do 
Cemitério de Vila Nova Cachoeirinha, Município de São Paulo. 2001.172 p. Tese (Doutorado em Geociências) - Instituto de Geociências, Universidade de São Paulo, São Paulo 2001.

MINISTÉRIO DO MEIO AMBIENTE. Águas subterrâneas, um recurso a ser conhecido e protegido. Brasília: MMA, 2007.

NEIRA, D. F.; TERRA, V. R.; SANTOS, R. P.; BARBIÉRI, R. S. Impactos do necrochorume nas águas subterrâneas do cemitério de Santa Inês, Espírito Santo, Brasil. Revista Natureza On Line, Vol.6, p. 36-41, 2008.

PACHECO, A. Os cemitérios e o ambiente. Revista Conselho em Revista - CREA RS, Vol. 24, p. 30, 2006.

SILVA, LEZÍRO M. Cemitérios: Fonte Potencial de Contaminação dos Aqüíferos Livres. Montevidéu:

ALHSUD, 1998.

WEBER, D. P. Análise da normatização acerca da implantação de cemitérios. 2010. 39f. Dissertação (Especialização em Gestão Ambiental) - Área de Ciências Naturais e Tecnológicas, Centro Universitário Franciscano, Santa Maria, 2010. 